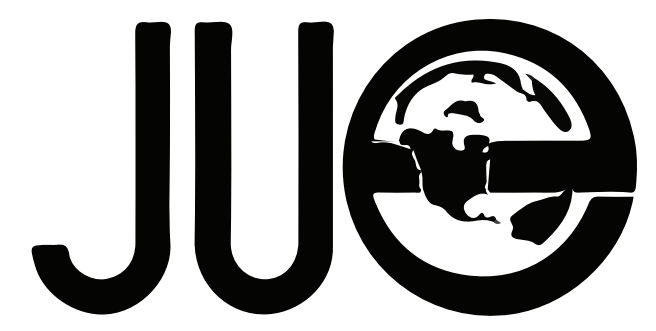

The Journal for Undergraduate Ethnography

Volume 6 | Issue 2

ISSN 2369-8721

\title{
Untangling the Web of Food, Class, and Culture: An Ethnographic Analysis of the Farmers' Market in Lexington, Kentucky
}

\section{Jamie Vescio}

Transylvania University, jlvescio@gmail.com

\section{ABSTRACT}

his paper examines the concept of class, the role power plays in defining class structures, and the implications of this process of construction within the context of food consumption. Both power and class are embedded in historical frameworks that this paper

explores through an ethnographic analysis of the Farmers' Market in Lexington, Kentucky. The research raises questions on the definitions of nature and organic food, the role of the economy within this process of defining, how these definitions come to serve as an embodiment of power, and the consequences for those who can afford neither organic food, nor the lifestyle that has come to accompany it. In addressing these questions, this paper seeks to historicize the construction of the organic food industry by exploring a more fluid, rather than essentialist, approach to the subjectivities that emerge within the industry while providing a context for exploring the otherwise limited perceptions of class and organic food. Through an anthropological lens, this paper attempts to deconstruct the Farmer's Market, organic food, culture, and class-driven inequalities. 
The exchange of people, materials, ideas, and more seems to increase with every passing moment. As knowledge travels from place to place or from person to person-particularly through the development of technology-the world appears more intertwined and complex than ever. Yet the people, materials, and ideas that were once apparently imbued with static, intrinsic qualities now constantly shift and take on new connotations within this complex system of interaction. Although anthropologists seek to search for and unveil meaning within this complexity, others choose to mask such chaos and unpredictability by attempting to revert to simpler, more "natural" lifestyles. The organic food industry serves such lifestyle choices. In communities where one can find fast food restaurants or stores, such as Wal-Mart, at every corner, a Whole Foods or Trader Joe's appears to represent a haven away from the mainstream industrialized food industry.

The Farmers' Market in Lexington, Kentucky reflects an image of this idyllic return to nature in a city where the population, commerce, and fast-paced lifestyle have been growing significantly. Yet beneath the simplicity and romanticism of locally grown food exist some not-so-natural intentions and consequences. In seeking to demonstrate a more "natural" way of living and eating, the Farmers' Market entangles itself within limiting perceptions of food consumption, economic disparities, the creation of an upper-class and an exclusive culture associated with organic food, and class and race-based inequalities. Using ethnographic data gathered in interviews with vendors, organic food consumers, and college students and staff members during fifteen weeks of research at the Farmers' Market and a local university in Lexington, Kentucky, I demonstrate that there is a politics of class and ethical consumption beneath the surface of the Farmers' Market and its consumers, resulting in an exclusive community segregated by class.

\section{Effects of Power and Class on Perceptions of Food}

Having grown up in Lexington, Kentucky, I often re-flect on the city's transformation. From the thriving art and mu-sic scene to the ever-increasing amount of microbreweries, what once appeared as a small town in the heart of the horse capital of the world has now made its way onto lists including Forbes' 2015 "Best Place for Business and Careers" and Wallet Hub's 2016 "Best Large City to Live In" (Commerce Lexington 2016). In its 2008 development plan, the Lexington-Fayette Urban County Govern-ment partnered with the Lexington Distillery District Foundation to write, "The Development Area seeks to cohesively establish the identity of Lexington's former bourbon corridor, thematically creating a dynamic Bluegrass asset that leverages history to drive tourism and conventions, attract the creative class, and serve as a local destination" (Lexington Distillery District Development Plan 2008). Downtown, in particular, represents a space for the development of food, art, commerce, socialization, and culture. Walking downtown one Saturday afternoon, I turn the corner and stumble upon a space that Lexington has come to claim as one of its staples-a distinct environment within this booming com-munity. Amidst hundreds of tall buildings, offices and businesses, restaurants, and busy streets, lies a large grey pavilion, home to the Farmers' Market. This pavilion and the numerous white tents beneath it are enough to portray an atmosphere of intentional ex-clusion from the chaos of the surrounding community, as vendors and consumers craft an image of a culture that values community, family, and simplicity.

With consumers sharing conversations in between their purchas-es, carrying fruits and vegetables in one hand while steering stroll-ers in the other, and leisurely walking around with their dogs, it appears as if the Farmers' Market fosters the opportunity to escape from the chaos of daily life and has been doing so since its instal-lation in 1975 (Lexington Farmers' Market 2012). Following the market's inauguration, the Farm and Garden Market Cooperative Association expanded its outreach through the creation of an 
additional satellite market at another location in Lexington (Lexington Farmers' Market 2012). Yet the downtown site remains the more popular of the two in terms of food, but more importantly, in terms of socializing. A deeper interpretation of what constitutes this particular environment reveals why Lexington residents both frequent, as well as identify with the culture of the downtown location. Geertz $(1973,5)$ defines culture as follows: "Believing, with Max Weber, that man is an animal suspended in webs of significance he himself has spun, I take culture to be those webs, and the analysis of it to be therefore not an experimental science in search of law but an interpretive one in search of meaning". In applying Geertz's operational perspective of culture to the Farmers' Market after my visit on a Saturday afternoon, I began to situate this seemingly simplistic and wholesome community as part of a larger structure.

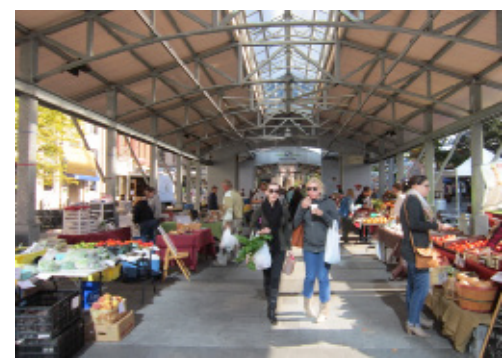

Figure 1. The Farmers' Market pavilion in downtown Lexington, KY. All photographs by the author.

During my visits to the Farmers' Market, I observed a concrete example of the romanticism that accompanies nature, wilderness, and organic food. The displays of fruits and vegetables, friendly vendors, and family-oriented environment presented consumers with the opportunity to momentarily escape the strictures of modern everyday life. For an hour or two, Farmers' Market consumers could return to a time when farming meant subsistence, livelihood, and wholesomeness. This idyllic scene and longing to return to simplicity and nature inevitably suggests a concern with current food practices. Akram-Lodhi (2014)) attributes this concern to capitalist market demands: "Many are particularly concerned with the nineteenth century origins of the global food regime, during which time predominantly subsistence-based peasant farmers were incorporated, often through imperialist force, into the world trading system and dependence on capitalist market imperatives" (153). Following this incorporation, the interest in new methods of conceptualizing and consuming food originally began as a counterculture to the food industry as a whole. As this occurred, the food distributors who once ignored the idea of "organic" or "natural" food eventually began promoting it upon realizing the newfound popularity among consumers (Belasco 2007).

Yet the story of the Farmers' Market and the organic food industry seems to be incomplete, due to its presentation, which masks the class structures involved at the consumption level. In speaking with people from different socioeconomic backgrounds, a consistently superficial and ahistorical representation of organic and natural food continued to arise, despite the diversity of the people discussing it. One of the first people whom I approached one Saturday afternoon was Abigail, a granola vendor who characterized nature and natural food as evoking "nice images of woods and water" (personal interview, October 10). With Lexington ranking as \#19 on Best College Reviews' "Best College Town in America" list (Commerce Lexington 2016), I also found it important to approach the large young-adult population at the Farmers' Market. I later asked Sarah, a student, to provide her definition of nature, in which she described "going for a hike and enjoying all the trees, streams, and wildlife I may find along the way" as the first thing that came to her mind (personal interview, October 21, 2015). These complementary approaches to naturalness reinforce what Cronon (1996) describes as the "frontier experience" that has played a role in the formation of American identity and shapes views towards nature: 
If wild land had been so crucial in the making of the nation, then surely one must save its last remnants as monuments to the American past...The curious result was that frontier nostalgia became an important vehicle for expressing a peculiarly bourgeois form of antimodernism. For the wild land was not a site for productive labor and not a permanent home; rather, it was a place of recreation. Wilderness suddenly emerged as the landscape of choice for elite tourists. The irony, of course, was that in the process wilderness came to reflect the very civilization its devotees sought to escape. (13)

In other words, the untouched and romantic images associated with natural food originate from a longing to maintain the American ideals of freedom, primitivism, and discovery. Yet the "bourgeois form of antimodernism" that Cronon discusses, alludes to the irony of such a mentality-for those who can afford to appreciate wilderness, or in this case the Farmers' Market and organic food, are often the very people who contribute to the perpetuation of the inequalities they wish to escape.

While Cronon (1996) applies the majority of his argument to wilderness, national parks, and tourism, his ideas also find applicability to food, particularly in the context of the organic food industry. Just as he describes nature as something both constructed and enjoyed by those who can afford it, organic food often represents this same methodical and exclusive way of living and eating. Although food is a basic component of life and survival, the decisions employed in deciding what to eat, in a context of relative abundance, speak to larger cultural norms and meanings at work. Bourdieu's (1989) habitus theory describes this very relationship through the concepts of structure and agency. For Bourdieu, those with power do not simply dictate the actions of individuals situated lower down the structure, but also work to reproduce the structure: "Each agent is a producer and reproducer of objective meaning," (p. 78). Structure is not separate from the agency and experiences of individuals-meaning that structures transfer power between agents, rather than onto agents. It is the agents themselves who maintain social control, for the symbolic elements-or cultural capital-one acquires by existing within a particular social class inevitably affect one's habitus (or embodied position within a culture), and therefore one's level of agency and power (Bourdieu, 1989, p. 17). In relation to the Farmers' Market, Bourdieu's concepts help to illustrate how the privilege of shopping at the Farmers' Market comes at both a monetary and cultural capital cost that is not afforded to all and is often beyond the reach of those from a more working-class background.

Sushi provides an example of how power and structure can turn seemingly "natural" food into a sign of social standing, as Bestor (2000) shows. Japan's transformation into a global economic hub in the 1970s paired with an American shift in favor of healthier food led to the emergence of the sushi fad in North America. What once represented an exotic, ethnic, and even unthinkable thing to eat (raw fish) now became popular, sophisticated, and in high demand. Sushi's global popularity as a manifestation of an upper-class lifestyle eventually began to transform the international fishing industry. With such a high demand for sushi across the globe, Japanese trading companies began buying their tuna from places outside of Japan, such as New England or Spain. Yet even with tuna originating from an outside location, it still maintains the façade of being a direct link to Japanese culture and to a higher-class identity (Bestor 2000). This global commodification of something that appears so natural to a particular culture is similar to the Farmers' Market in Lexington. Although growers and sellers of local food promote it as raw, pure, or untouched, its consumers may in fact be seeking to purchase this link to the upper class, in addition to the food itself. 
Food prices at the Farmers' Market, which are higher than in regular grocery stores, serve as the most direct example of this power and exclusion. However, a less visible layer of exclusion also exists in the form of the social and cultural capital, as Bourdieu would put it, required to even enter the market. Within the context of the Farmers' Market, cultural capital would include having the knowledge-base to understand and speak about organic food with vendors and fellow consumers, which often comes as a result of one's socioeconomic background, or habitus. Anthropologists often define these "sociocultural" barriers as examples of structural violence, in which structure helps to promote order, but also exclusion: "Structural violence is violence exerted systematicallythat is, indirectly-by everyone who belongs to a certain social order" (Farmer 2004, 307). Although the outdoor location of the Farmers' Market constructs an image of openness and inclusion, the race, socioeconomic status, and age of consumers of organic food and shoppers at the Farmers' Market consumers suggest a different story.

\section{Economic Structures as Determinants of Food Consumption}

The Lexington Farmers' Market seems to take a simple approach to food: visiting and purchasing its food appear to be choices available to all. The food industry, however, represents an intricate weaving of power and agency that affects choices made at multiple levels in the production and consumption processes. The exclu-sivity associated with organic food stems from practices that take place within a capitalist economy and result in unjust farming conditions and the labeling of organic food as an ethical counter-culture to the industrialized food industry.For Farmers' Market customers, directly purchasing from farmers allows them to place a face and a story to their food while participating in a "political ecology" (West 2012).
Although organic and local consumers may believe that their purchasing habits are not in the realm of capitalism, they very often follow narratives creat-ed by marketers seeking to attach morality, and therefore identity, to food:

Those who always buy fair-trade coffee may be trying to send the message that they care about the plight of rural farmers in the tropics, and those who buy coffee certified by the Rainforest Alliance may be trying to make a statement about their commitment to environment conservation...Today, people often attempt to derive and express identity and politics through the coffee and other commodities that they buy and serve. (West 2012, 18)

Similarly, for the Farmers' Market, consumers represent an ironic dynamic in which their attempt to escape the manipulation of capitalism by associating with a particular counterculture only reproduces class positions due to the demographic to which the Farmers' Market caters:

I think it makes great contributions to Lexington and the Bluegrass in terms of engagement with local business, but I do have guilt that it is a place for upper-class people to bask in their vanity. The socioeconomic division is evident when there. I think that, like the organic food business, the Farmer's Market caters to people with more money. It is sad that everyone can't enjoy the same experience. Most of the goods there are a luxury. (Sarah, personal interview, October 21, 2015)

Those who shop at the Farmers' Market inevitably make a statement about their identity and class association when choosing to participate in such an exclusive activity. As noted by many Lexington natives, such as Sarah, organic food and the Farmers' Market are in fact a luxury hidden beneath a "natural" presentation. 
As I left the Farmers' Market one morning, I began to wonder what the shift from supermarkets to organic food meant for those who could not afford to make the transition. When I sat down to interview Rhonda, a university staff member who works as a dining hall greeter and cleaner and who seemed to personify a contrast to the socioeconomic background of the majority of Farmers' Market consumers, I expected to hear a limited perspective. What unfolded however, was a conversation rich in Rhonda's observation of a lifestyle in which she could not participate:

When I think about organic I think about expensive. I've been to a farmers' market, but not the one downtown. It used to be the one over here off of Limestone. I guess it was more like a vegetable stand at that time. I'm forty-four years old so at that time we called it the vegetable stands. Farmers' Market is just like the vegetable stand. Back then we called it the vegetable stand and now they done upgraded it to the Farmers' Market. (personal interview, October 14, 2015)

Rhonda's juxtaposition of the term "vegetable stands" to "farmers' market" symbolizes the self-consciousness of the rise in organic food in the context of an industrial food system. While it appears that the Farmers' Market provides a haven from modern industrial life_-going "back to the land" - its primarily affluent consumers suggest that the wealthy simply found their next demand: organic food. Hébert uses salmon as an example of how societies come to craft their demands and perceptions of nature:

In order for wild salmon to be made distinctive, it must be remade to meet aesthetic and technical norms largely established by the farmed salmon industry... In critical respects, singular salmon replicates the very economic forms to which it is positioned as an alternative, and materializes novel social distinctions in sites of production. $(2010,553)$
In the same way, the various actors of the Farmers' Market position organic and local food as more thoughtful alternatives to current food practices while simultaneously replicating conventional structures of class.

The college students whom I interviewed exhibited a much different perspective than those from working-class backgrounds, like Rhonda, who could not afford to buy their food from the Farmers' Market. One student said:

I think a lot of people think of organic food in terms of produce, as well as seeing it as a trendy thing to do... farmers' markets are a great way to see a sense of community and happiness within a town. I hope the trend keeps rising, and there will be more farmers' markets that continue to grow in the upcoming years. (personal interview, October 14, 2015)

The Farmer's Market certainly does create a sense of community and has contributed to a new and thriving downtown Lexington, Kentucky. However, this perhaps only comes with the happiness of a select few. Economic exclusion directly contributes to the popularity of the Farmers' Market, as people come to value the cultural capital of these products. While the Farmers' Market environment seems community-oriented, so long as its customers assign its produce such high symbolic value, many members of the Lexington community will continue to feel morally devalued as a result of their inability to purchase more "humane" food, thus creating a hierarchy both between food types and among people. 


\section{Forming Identity through Food}

The creation of a hierarchy based on where one buys one's food affects the consumer's identity. Identity-making occurs within many types of spaces, and has many facets; however, it frequently results in moments that define notions of culture and one's position within a particular system, such as a class system. Ogden highlights this very idea as part of a spatial philosophy: "Deleuze and Guattari insist that the world's properties (material, semiotic, human, and nonhuman) come into being only through their relations" $(2011,29)$. Food practices are one such arena in which these relations form. Whether at the dinner table, the checkout line of a supermarket, or-in this case-the Farmers' Market, food brings together species in assemblages that "dissolve and displace the boundaries of nature and culture" (ibid., 29). The relations that take place within the Farmers' Market both contribute to identity formation and speak to what this might then mean for the community as a whole, including the reproduction of class-based inequalities. The market acts not so much as a simple source of food, but as a very particular and often exclusive social setting.

As a native of Lexington, I visited the Farmers' Market with my family almost every weekend. Throughout my visits, I remember feeling the mysticism of talking to farmers and vendors or picking out fruits and vegetables. Yet returning to the Farmers' Market from an anthropological perspective complicated this original idyllic scene. Along the way, I met Anthony, the owner of a local olive oil company. What initially intrigued me about Anthony and his table at the Farmers' Market was the very product he sold. Although Anthony claimed to produce the oils himself, olive oil certainly did not coincide with the typical products that one associates with a farmers' market. Yet the more I listened to Anthony speak about his fellow vendors, the more I began to realize that the majority of the products at the Farmers' Market were neither "natural" nor directly from a farm.
It's kind of like a family in a lot of ways and you get to know people. At the [Farmers' Market] on Sundays we're across from the bubble tea guy and a local pasta booth is right by us. Whereas here, we set up right here and get to know some other vendors. The lady right across from us sells lamb and I sometimes get her stuff. Like these flowers right here came from this lady right here. I'm gonna give these to my girlfriend. (personal interview, October 17, 2015)

Items such as bubble tea, lamb, flowers, wine, and olive oil all cater towards a certain consumer. While the Farmers' Market might attempt to reach the Lexington community as a whole, the vendors and their products point to a particular, class-specific presentation and aesthetic. In her discussion of trends and authenticity within consumerism, Michael deconstructs individual agency within identity formation and instead places supposed personal authenticity within a larger framework of social relations: "While differences in taste and lifestyles are often perceived as inherent characteristics of one's personality, Bourdieu has shown how these originate from differences in social positions" $(2015,164)$. Despite its unique, "pure", and "authentic" appeal, the popularity of the Farmers' Market and its products continues so long as its accessibility remains confined to those who hold a specific social position.

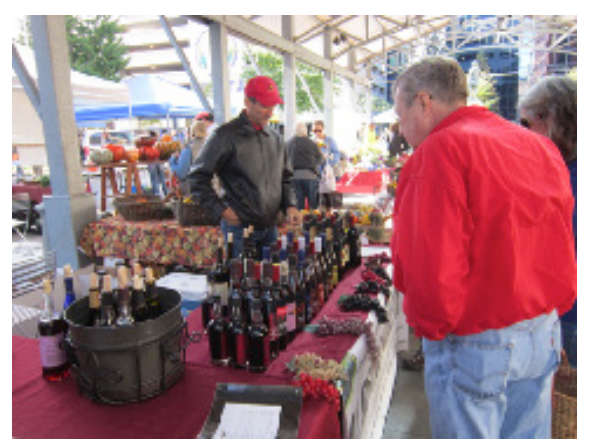

Figure 2. Shoppers stopping to look at a wine booth. 
The interactions among species at the Farmers' Market point to factors that help to deconstruct this façade. Although organic food attempts to keep food in its "natural" state, in propping up a certain counterculture, the Farmers' Market defines itself not only by its food but also by the socializing and identity-making that occur within its boundaries. Each time I return to the Farmers' Market I see a similar demographic: young couples with dogs or young couples with children. Although the dogs remain leashed and tame, they serve a particular and significant role as refrains, or repeated figures of entanglement, that contribute to the interspecies interactions and socialization within the Farmers' Market (Ogden 2011). During one of my trips to the Farmers' Market I met Jackie, a sales representative for an artisan cheese company. Looking to get involved with local businesses and non-profits, Jackie landed her position as a vendor after approaching the owner of the company about the possibility of helping him with sales and marketing. What began as a way to support her local economy eventually evolved into an enjoyment of the atmosphere of the Farmers' Market:

That's actually been a fun part of this job for me. I like dogs and there are usually as many dogs as there are people and that ends up causing people to interact with one another because of their dogs. I also think there's a nice community among the vendors. There's a lot of camaraderie. There's a good mood-we're outside. It's a very positive vibe. (personal interview, October 17, 2015)

These moments of interaction speak to the role the Farmers' Market plays within the Lexington community in bringing together members of a specific class and socioeconomic background for what can be thought of as an exclusive day of shopping, relaxation, and socializing. With the downtown location only being open on Saturdays, consumers undoubtedly rely on other food sources to sustain themselves throughout the week. The Farmers' Market must therefore serve a purpose beyond simply providing food.

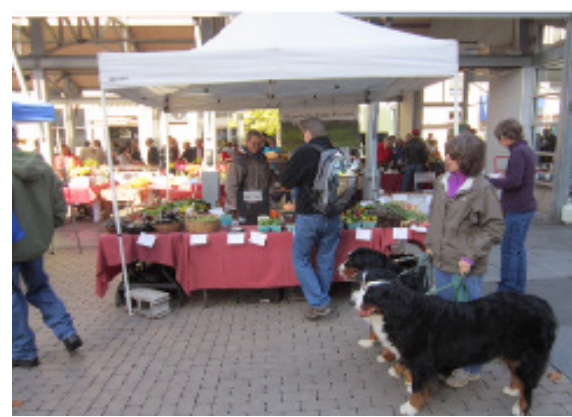

Figure 3. A Farmers' Market visitor and her dogs.

This purpose seems to suggest a tourist atmosphere in which consumers enjoy passing through and interacting with others as much as-if not more than-actually purchasing food. Oddly enough, "farmers' market guides" constitute their own literary genre and possess striking similarities to a typical travel or vacation guide. MacLachlan shares the story of her seasonal markets and farmstands tour throughout the Midwest: "This was the moment I fell in love with real strawberries, and with my farmers' market. To this day I have yet to be convinced that any supermarket, even those rare ones that favor organic and local growers, come anywhere close to the open-air experience of discovering a new love" $(2012,2)$. The romance MacLachlan attaches to visiting her farmers' market relates to the intimacy within spaces of interspecies contact: "Yet multispecies zones of contact are both intimate, as the tactile immediacy these ethnographies of companionship and domestication evoke, and bound up in global multispecies diasporas and processes of change" (Ogden, Hall, and Tanika 2013, 11). The Farmers' Market serves as such a contact zone in which interactions between species appear both simple, yet entangled within the larger context of a politics of consumption driven by class exclusivity. 
As an example, despite its wholesome appeal, the natural products of the Farmers' Market often follow the same marketing strategies that organic food consumers seem to think they are escaping. Belasco deconstructs these marketing strategies by analyzing how mainstream businesses turn granola, herbal tea, and other once-"revolutionary" food items into profitable products: "In the countercuisine, 'natural' had three dimensions: content (more nutrients, no chemicals), time (older), and a state of mind (nonrational, romantic, improvisational)" (2007, 220). Ben's thoughts resonated with Belasco's last dimension especially, as he answered my questions about the Farmers' Market from a student's perspective:

I love the Farmers' Market because it brings together all kinds of local people through their passions. It's a fun atmosphere that's close by. They have already made food, produce, art, wine. Everyone seems to care about what they make and can give their story behind it. Knowing where these things come from makes you feel more comfortable and makes you care about what you buy. (personal interview, October 13, 2015)

In discussing his second dimension-time-Belasco elaborates on how antimodernism grew as a counterculture and how organic food marketers cater to this trend. As antimodernism increased in popularity, processors began to limit nature to words like "valley," "country," “farm," grandma," "hearth," and "old-fashioned" (2007, 221). One shopper with whom I spoke used strikingly similar words to describe the atmosphere of the Lexington Farmers' Market: "It's pleasant, quaint, friendly, homey" (personal interview, October 17, 2015). This limited view of nature provides context to Pollan's discussion of the aesthetics and presentation of supermarkets:
Spritzed with morning dew every few minutes, produce is the only corner of the supermarket where we're apt to think "Ah, yes, the bounty of Nature!" Which probably explains why such a garden of fruits and vegetables (sometime flowers, too) is what usually greets the shopper coming through the automatic doors. (Pollan 2006, 15)

The organic food industry follows this same tendency to manipulate its presentation for the upper-class consumer who believes they are making an individual and intentional economic decision when choosing to shop at the Farmers' Market.

Indeed, consumers come to view their actions as autonomous, rather than structured. This directly reflects West's (2012) discussion of political ecology, in which individuals seek to demonstrate their agency by making "conscious" purchasing decisions. Yet even organic food deeply embeds itself in a system of "signs, symbols, representations, images, and fantasies that exist interlaced with the money economy" (West 2012, 24). Through the ethical dimension assigned to organic food, purchasing from the Farmers' Market allows consumers to maintain their social and moral ties while forgetting that their consumption constitutes a luxury for others:

Rather than acknowledge that high cost makes farmers market patronage an impossibility for many low-income people, market participants tend to cast food purchasing decisions as a matter of individual choice... The market's high prices make it more likely that whites, who tend to be more affluent, will shop there. By positing farmers market shopping as an ethical imperative, yet not acknowledging the class exclusivity of this practice, farmers market participants reinforce what Wacquant calls the "moral inferiority of the poor" and by extension, the moral superiority of affluent whites. (Alkon and McCullen 2011, 950) 
In that sense, organic food is not just a market established by agentive individuals, but is reproduced by structured groups that directly contribute to identity-making and reproduction.

\section{Power, Class, and Exclusion}

The class structures that characterize consumers of the Farmers' Market inevitably leave out certain members within the Lexington community-particularly those who can neither afford the food, nor the lifestyle of the typical shopper. The racial and socioeconomic distribution of the consumers provides enough of a context to suggest that the accessibility of the Farmers' Market is perhaps deeply embedded in the historical race and class-driven exclusion of certain members within the United States and Lexington. In a case study conducted at a community-supported agriculture (CSA) market in New Orleans, researchers found a similar trend of objectified marginalization:

Interview and ethnographic observation data indicate a general consensus on the economic constraints, but some non-resident supporters of the organization attributed the issue to lack of knowledge about the food system or the benefits of local food consumption. The residents, on the other hand, pointed to spatial and sociocultural barriers that made the market and its location less accessible to them, including the produce selection and purchase options, convenience of access to the market, and the race-related historical and spatial context of the market's location. (Kato 2013, 369)

In the process of formulating knowledge, certain histories are often left out. The association of nature, organic food, and the Farmers' Market with a singular, upper-class image, serves as an example of how crafting "ideal" knowledge often involves the removal of a culture's history and an escape from responsibility:
It is as if ecological fame-making is a process that effaces all other landscape visions from our popular consciousness, turning the landscape into what Bruno Latour called a "smooth object." Smooth objects, Latour explained, are materialities containing clearly defined boundaries and essences, "matters of fact," belonging "without any possible question to the world of things, a world made up of persistent, stubborn, non-mental entities defined by strict laws of causality, efficacy, profitability, and truth. (Ogden 2011, 118)

The Farmers' Market manifests itself as a smooth object with words like "pleasant, quaint, friendly, and homey" being used to describe it in a "matter of fact" manner. Yet these words ignore the historical reality of a space whose accessibility is limited by class. As a result of ignoring the complexity of the knowledge on organic food, the Farmers' Market overlooks inequality within food systems and promotes an exclusivity that indirectly results in poor nutrition for others.

When Rhonda first mentioned "vegetable stands" as the terminology she used to describe the farmers' market she visited, I began to wonder what the words "organic food" meant to consumers, as well as people like Rhonda who did not frequent the downtown location. Rhonda's friend, Tiffany, represented a similar farmers' market experience at her location that conflicted with the pristine white tents, display tables, and pavilion at the downtown location:

I ain't been to the one downtown in years, but I go to that one on Maxwell. People set things up in their trucks and you walk around and see what you want, see who's the best price, see who looks the best. This summer I stayed up there because they had watermelons. They were like $\$ 6$. They were the best. (personal interview, October 14, 2015) 
Both Rhonda and Tiffany suggest that there is something unique about the downtown location that sets it apart from their own farmers' markets or vegetable stands. This difference perhaps originates from a particular presentation that the downtown location continually promotes. Hughner, McDonagh, Prothero, Shul$\mathrm{tz}$, and Stanton identify high price as an ambiguous, yet key factor that both deters and encourages the purchasing of organic food: "While consumers indicate the high price of organic food to be prohibitive in their purchasing behaviors, they use price to form opinions about the quality and taste of organic food items...high price meant better quality" $(2007,103)$. As the price of organic food limits people like Rhonda and Tiffany to working-class vegetable stands, it encourages others to buy into the upper-class lifestlye of organic food consumption. The downtown Farmers' Market operates within this same zone of cultural significance.

With issues of class insinuating into the Farmers' Market, additional structural barriers also permeate through the organic food culture-specifically race. The tents were certainly not the only overwhelmingly white component of the Farmers' Market. During one of my visits, I noticed a mere three African Americans among a sea of white people. In assuming an upper-class connotation, the Farmers' Market reflects and perpetuates racialized perceptions of organic food: "many of the discourses of alternative food hail a white subject and thereby code the practices and spaces of alternative food as white" (Akon and Agyeman 2011, 264). The majority of the university food staffers with whom I spoke, and who had not visited the downtown Farmers' Market, were African American, despite Lexington as a whole being approximately 81 percent white (US Census). What appears as such a "natural" weekend activity for white members of the Lexington population may be a foreign activity for others, as demonstrated by Tiffany's limited knowledge of organic food as a whole:
I was looking at a program on TV-I think it was Dr. $\mathrm{Oz}$ - and he had a man on the show who said that even though it says, "natural," it's not. He said it's organic; you have to get the organic stuff because the natural still has stuff in it that's not right or something that we shouldn't eat. They're still throwing something off guard in it. So natural, when you see that word it ain't so. It's best to go with the organic. (personal interview, October 14, 2015)

The racial demographic of the Farmers' Market reflects the historical context of accessibility. As the affluent continue to associate high price with quality, organic food will maintain a predominantly white consumer base at the exclusion of others.

Many of the vendors and shoppers at the Farmers' Market were attuned to the discrepancies in both race and class within the demographic of organic food consumers. Yet despite the awareness of the situation, there remained a matter-of-factness and sense of complacency in their overall attitude toward the Farmers' Market and its accessibility: "I think it's more of a dollars and cents issue. I mean this isn't Wal-Mart and when something is less money that's a decision you have to make" (personal interview, October 17, 2015) said Jackie, who, along with many other vendors, recognized the class and racial distribution of the Farmers' Market, but suggested no urgency for change. In other words, it seemed as though they enjoyed the quaint atmosphere that exclusion allowed. Jackie did, however, shed light onto an important component of the Farmers' Market: that exclusion is in fact a "dollars and cents issue." In describing where she purchases her own food from, Rhonda embodied this reality:

I go to three different stores. I go to Kroger's. I go to Aldi's. I go to Save-A-Lot. A gallon of milk over at Aldi's is a $\$ 1.69$, honey, but the difference with Aldi's is they do not bag. You have to bag your own. So a lot of people bring in boxes. And they sell bags too. The brown ones 
the time people bring their own boxes in. The economy is so rough right now. That's the reason why I go to all those stores. Like Kroger's their milk is probably \$2.29, Save-A-Lots is probably $\$ 2.09$. And you can probably get a whole gallon from Aldi's for $\$ 1.69$. So that's why I go to all the different stores. Like Kroger's, they have my bread for like $\$ 0.99$ and everybody else wants a $\$ 1.25$ for a loaf of bread. So that's why. Nowadays you gotta take your money and split it up. That's the reason why I do typically different stores. (personal interview, October 14, 2015)

Farmers' Market consumers apparently have a sense of agency in deciding where to purchase food and how to utilize this act of purchasing as a means for socializing. In contrast, Rhonda's internalization of the price of food embodies the racial, economic, and societal barriers preventing her from shopping at the Farmers' Market and from buying into the organic food lifestyle.

With Rhonda and Tiffany remaining marginalized from the Farmers' Market, this raises the question of what they, as well as others, can and do in fact consume. With organic food remaining exclusive to those who can afford its high price, many are left with not only cheaper, but also unhealthy options. In a sense, the Farmers' Market represents a space in which identity and politics merge. In crafting an exclusive counterculture, the Farmers' Market prevents outsiders from accessing what some constitute as a basic human right: healthy and nourishing food. The discrepancy in food justice does not appear to be slowing down: "The number of people going hungry has grown dramatically in the U.S., increasing to 48 million by 2012-a fivefold jump since the late 1960s, including an increase of 57 percent since the late 1990s. One in six [people] reports running out of food at least once a year" (McMillan 2015). Yet what it means to be "healthy" or to be "hungry" intermingles within a complex system of identity formation. Just as symbols govern the aesthetic of the Farmers'
Market, so too do they permeate other aspects of the food industry, including the relation between food and body image. In National Geographic, McMillan (2015) reports on the connection between aesthetic and the willingness of a society to accept something - in this case malnutrition - as a true phenomenon:

The answer is "this paradox that hunger and obesity are two sides of the same coin," says Melissa Boteach, vice president of the Poverty and Prosperity Program of the Center for American Progress, "people making trade-offs between food that's filling but not nutritious and may actually contribute to obesity." For many of the hungry in America, the extra pounds that result from a poor diet are collateral damage-an unintended side effect of hunger itself. (McMillan 2015, para. 9)

With many of America's "hungriest" deviating from symbols of the "gaunt-faced unemployed scavenging for food on urban streets" (ibid., para. 6) a deceitful food reality seems to have emerged, allowing the other end of the spectrum-Farmers' Market consumers-to continue living through their romanticized depictions of nature.

\section{Conclusion}

This depiction of the Farmers' Market speaks to a larger structure at play comprised of a simplistic view of food, class, and inequality. Living in Lexington my entire life, visits to the Farmers' Market on Saturday mornings became commonplace for my family and me-a sort of ritual. As a result of the frequency of these visits, questioning my position, as well as the position of others at the Farmer's Market, never entered my mind as something worth considering. Yet returning with an anthropological lens provided the tools for reinterpreting the familiarity of this environment. The Farmers' Market may be a counterculture, but it still presents a culture nonetheless, meaning that its consumers both create and suspend themselves in its webs of significance (Geertz 1973). 
The Farmers' Market finds its value through the meaningful acts of exchanges that can be enacted within it (West 2012). Yet the process of meaning-making extends beyond the boundaries of the grey pavilion, of downtown, or even of Lexington, as it moves through a class system that associates consumption with morality, politics, and identity.

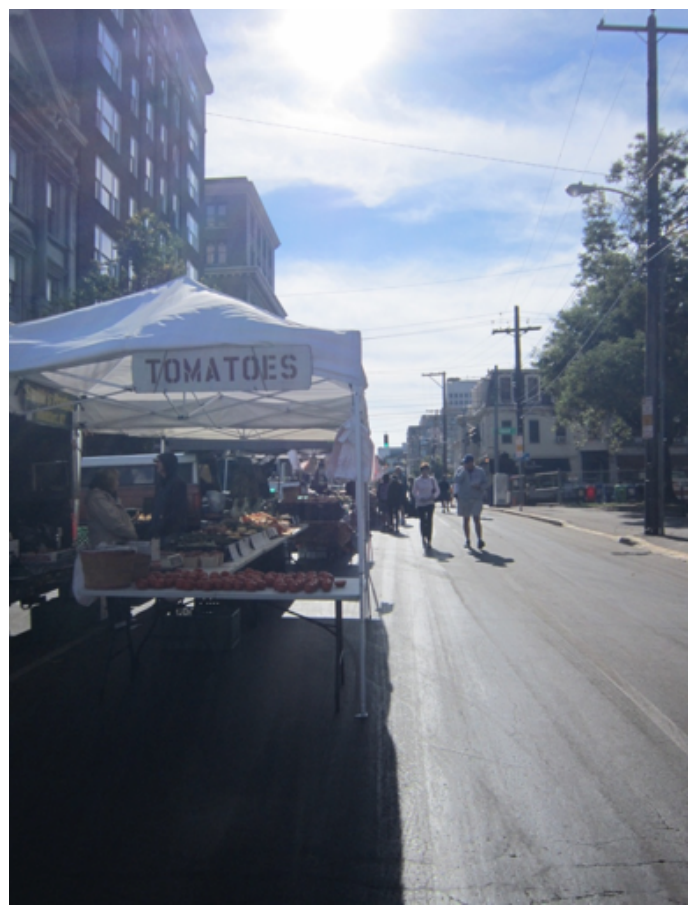

Figure 4. Farmer's Market tents outside of the pavilion. 


\section{Acknowledgements}

I would like to thank the Lexington Farmers' Market and its vendors for allowing me to learn from them and their experiences, as well as the other members of the Lexington community who agreed to be interviewed. My deepest thanks goes to my professor, Dr. Hande Ozkan, for her continued investment in my education and for never ceasing to remind me of the significance and relevance of anthropology.

\section{REFERENCES}

Akram-Lodhi, Haroon. 2013. Hungry for Change: Farmers, Food Justice, and the Agrarian Question. Black Point, Nova Scotia: Fernwood.

Alkon, Allison Hope, and Agyeman, Julian. 2011. Cultivating Food Justice: Race, Class, and Sustainability. Cambridge: MIT Press.

Alkon Allison Hope, and McCullen, Christie Grace. 2011. "Whiteness and Farmers Markets: Performances, Perpetuations...Contestations?” Antipode 43:937-959.

Belasco, Warren James. 2007. Appetite for Change: How the Counterculture Took on the Food Industry. Ithaca: Cornell University Press.

Bestor, Theodore C. 2000. "How Sushi Went Global." Foreign Policy 121: 54-63.

Bourdieu, P. (1989). “Social Space and Symbolic Power." Sociological Theory 1:14-25.

Commerce Lexington. 2016. "Bluegrass Rankings." Commerce Lexington. Accessed July 26, 2016. http://www.locateinlexington.com/bluegrassrankings.aspx.

Cronon, William. 1996. "The Trouble with Wilderness; Or, Getting Back to the Wrong Nature." In Uncommon Ground: Rethinking the Human Place in Nature, 7-28. New York: W.W. Norton \& Co.

Farmer, Paul. 2004. "An Anthropology of Structural Violence." Current Anthropology, 45(3):305-25.

Geertz, Clifford. 1973. “Thick Description: Toward an Interpretive Theory of Culture. The Interpretation of Cultures, 3-30. New York: Basic Books.

Hébert, Karen. 2010. "In Pursuit of Singular Salmon: Paradoxes of Sustainability and the Quality Commodity.” Science as Culture 19(4):553-81.

Holmes, Seth M. 2013. Fresh Fruit, Broken Bodies: Migrant Farmworkers in the United States. Berkeley: University of California Press.

Hughner, Renée Shaw, Pierre McDonagh, Andrea Prothero, Clifford J. Shultz, and Julie Stanton. 2007. "Who are Organic Food Consumers? A Compilation and Review of Why People Purchase Organic Food." Journal of Consumer Behaviour 6(2-3):94-110.

Kato, Yuki. 2013. "Not Just the Price of Food: Challenges of an Urban Agriculture Organization in Engaging Local Residents." Sociological Inquiry 83(3):369-91. 
Lexington-Fayette Urban County Government \& Lexington Distillery District Foundation. 2008. "Lexington Distillery District Tax Increment Financing Development Area \& Plan.” The Lexington Distillery District. Accessed July 26, 2016. http://www.lexingtondistillerydistrict.com/LDD_ DevPlan_10-13-08_Web.pdf

Lexington Farmers' Market. 2012. “Our History.” Accessed October 2, 2015. http:// www.lexingtonfarmersmarket.com/index-4.html.

MacLachlan, Janine. 2012. Farmers' Markets of the Heartland. Urbana: University of Illinois Press.

McMillan, Tracie. 2015. “The New Face of Hunger." National Geographic, 2015-2016 Accessed October 20, 2015. http://www.nationalgeographic.com/ foodfeatures/hunger/

Michael, Janna. 2015. "It's Really Not Hip to Be a Hipster: Negotiating Trends and Authenticity in the Cultural Field.” Journal of Consumer Culture 15(2): 163-82.

Ogden, Laura A. 2011. Swamplife: People, Gators, and Mangroves Entangled in the Everglades. Minneapolis: University of Minnesota Press.

Ogden, Laura A., Billy Hall, and Kimiko Tanita. 2013. "Animals, Plants, People, and Things: A Review of Multispecies Ethnography." Environment and Society: Advances in Research 4(1): 5-24.

Pollan, Michael. 2006. The Omnivore's Dilemma: A Natural History of Four Meals. New York: Penguin Press.

U.S. Census. 2012. "Lexington-Fayette, Kentucky Statistics and Demographics.” Area Connect. Accessed July 26, 2016. http://lexingtonky.areaconnect.com/ statistics.htm.

West, Paige. 2012. From Modern Production to Imagined Primitive: The Social World of Coffee from Papua New Guinea. Durham: Duke University Press.

This work is licensed under a Creative Commons Attribution-NonCommercial NoDerivs 4.0 International License. 